\title{
Prognostic and Predictive Factors in Advanced Urothelial Carcinoma Treated with Immune Checkpoint Inhibitors: A Review of the Current Evidence
}

\author{
Sara Elena Rebuzzi ${ }^{1,2, *,+}$ (D) Giuseppe Luigi Banna ${ }^{3,+}\left(\mathbb{D}\right.$, Veronica Murianni ${ }^{4}$, Alessandra Damassi ${ }^{5}$, \\ Emilio Francesco Giunta ${ }^{6}$ D , Filippo Fraggetta ${ }^{7}$, Ugo De Giorgi ${ }^{8} \mathbb{D}$, Richard Cathomas ${ }^{9}$, Pasquale Rescigno ${ }^{10} \mathbb{C}$, \\ Matteo Brunelli ${ }^{11}$ and Giuseppe Fornarini ${ }^{4}$ (D)
}

check for updates

Citation: Rebuzzi, S.E.; Banna, G.L.; Murianni, V.; Damassi, A.; Giunta, E.F.; Fraggetta, F.; De Giorgi, U.; Cathomas, R.; Rescigno, P.; Brunelli, M.; et al. Prognostic and Predictive Factors in Advanced Urothelial Carcinoma Treated with Immune Checkpoint Inhibitors: A Review of the Current Evidence. Cancers 2021, 13, 5517. https:// doi.org/10.3390/cancers13215517

Academic Editors: José I. López and Kazumasa Matsumoto

Received: 2 October 2021

Accepted: 1 November 2021

Published: 3 November 2021

Publisher's Note: MDPI stays neutral with regard to jurisdictional claims in published maps and institutional affiliations.

Copyright: (c) 2021 by the authors. Licensee MDPI, Basel, Switzerland. This article is an open access article distributed under the terms and conditions of the Creative Commons Attribution (CC BY) license (https:/ / creativecommons.org/licenses/by/ $4.0 /)$.
Medical Oncology, Ospedale San Paolo, 17100 Savona, Italy

2 Department of Internal Medicine and Medical Specialties (Di.M.I.), University of Genova, 16132 Genova, Italy Candiolo Cancer Institute, FPO-IRCCS, 10060 Candiolo, Italy; gbanna@yahoo.com

4 Medical Oncology Unit 1, IRCCS Ospedale Policlinico San Martino, 16132 Genova, Italy; murianni.veronica@gmail.com (V.M.); giuseppe.fornarini@hsanmartino.it (G.F.)

5 Academic Unit of Medical Oncology, IRCCS Ospedale Policlinico San Martino, 16132 Genova, Italy; alessandra.damassi@gmail.com

6 Department of Precision Medicine, Università Degli Studi della Campania Luigi Vanvitelli, 80131 Naples, Italy; emiliofrancescogiunta@gmail.com

7 Pathology Department, Ospedale “Gravina", 95041 Caltagirone, Italy; filippofra@hotmail.com

8 Department of Medical Oncology, IRCCS Istituto Romagnolo per lo Studio dei Tumori (IRST) "Dino Amadori", 47014 Meldola, Italy; ugo.degiorgi@irst.emr.it

9 Division of Oncology/Hematology, Kantonsspital Graubünden, 7000 Chur, Switzerland; richard.cathomas@ksgr.ch

10 Interdisciplinary Group for Translational Research and Clinical Trials, Urogenital Cancers GIRT-Uro, Candiolo Cancer Institute, FPO-IRCCS, Candiolo, 10060 Turin, Italy; pasquale.rescigno@ircc.it

11 Department of Diagnostics and Public Health, Section of Pathology, University and Hospital Trust of Verona, 37134 Verona, Italy; matteo.brunelli@univr.it

* Correspondence: saraelena89@hotmail.it

+ These authors equally contributed as first co-authors.

Simple Summary: Despite immune checkpoint inhibitors' (ICIs) improved overall survival in urothelial carcinoma patients, only a minority of them benefit from immunotherapy. Therefore, there is an unmet clinical need to identify biomarkers which are useful to select the patients who are most likely to respond to ICIs. This review describes the prognostic and predictive role, and potential clinical applicability, of patient- and tumour-related factors. These factors include new molecular classes, tumour mutational burden, mutational signatures, circulating tumour DNA, programmed death-ligand 1, inflammatory indices and clinical characteristics. This summary may help clinicians to assess patients who are considered for ICI treatment, and may drive further prospective research on these biomarkers.

Abstract: In recent years, the treatment landscape of urothelial carcinoma has significantly changed due to the introduction of immune checkpoint inhibitors (ICIs), which are the standard of care for second-line treatment and first-line platinum-ineligible patients with advanced disease. Despite the overall survival improvement, only a minority of patients benefit from this immunotherapy. Therefore, there is an unmet need to identify prognostic and predictive biomarkers or models to select patients who will benefit from ICIs, especially in view of novel therapeutic agents. This review describes the prognostic and predictive role, and clinical readiness, of clinical and tumour factors, including new molecular classes, tumour mutational burden, mutational signatures, circulating tumour DNA, programmed death-ligand 1, inflammatory indices and clinical characteristics for patients with urothelial cancer treated with ICIs. A classification of these factors according to the levels of evidence and grades of recommendation currently indicates both a prognostic and predictive value for ctDNA and a prognostic relevance only for concomitant medications and patients' characteristics. 
Keywords: advanced urothelial carcinoma; immune checkpoint inhibitor; immunotherapy; prognostic; biomarkers; tumour mutational board; genomic signatures; ctDNA; PD-L1; inflammatory indices

\section{Introduction}

Worldwide, urothelial carcinoma (UC) represents the seventh most common cancer and the ninth most deadly tumour, with about 212,000 related deaths [1].

For a long time, the only effective treatment of metastatic UC (mUC) was platinumbased chemotherapy, which is still the standard of care in the first-line setting [2]. In recent years, the treatment landscape of mUC has been changed profoundly by the introduction of immune-checkpoint inhibitors (ICIs) [3] and, even more recently, antibody-drug conjugates (anti-nectin 4 and anti-Trop2) [4] and FGFR inhibitors [5].

Since 2016, the U.S. Food and Drug Administration (FDA) has approved two monoclonal antibodies targeting PD-1 (nivolumab and pembrolizumab) and three antibodies targeting PD-L1 (atezolizumab, avelumab, and durvalumab) for mUC [6].

The introduction of these new drugs urges the identification of potential biomarkers which are able to select the patients most likely to respond to immunotherapy. Promising prognostic and predictive factors in patients with mUC treated with ICIs include clinical features, new tumour molecular classes, the tumour mutational burden (TMB), mutational signatures, circulating tumour DNA (ctDNA) and programmed death-ligand 1 (PD-L1). Despite the increasing number of biomarkers under investigation, these factors still need validation for their application in clinical practice.

In this review, we summarize the landscape of clinical, molecular and genomic determinants of the prognosis and response to ICIs in patients with mUC. A classification of these factors by their prognostic and predictive value according to levels of evidence and grades of recommendation [7] based on the available evidence has been attempted.

\section{Molecular Factors}

\subsection{Molecular Classes}

Muscle-invasive bladder cancer (MIBC) is a heterogeneous disease characterized by genomic instability and a high mutation rate [8]. In this scenario, transcriptome profiling may be helpful with the classification of UC into molecular subtypes in order to stratify the prognosis more precisely and drive more effective therapeutic choices. Indeed, the assumption for a molecular tumour classification is the understanding of cancer biology by identifying the specific genomic alterations of which the molecular subtypes are enriched, and which could be clinically significant as prognostic and druggable [9].

Several molecular classifications have been attempted for UC, advancing our knowledge about its biology [9]. The response to chemotherapy and immunotherapy may be enriched in specific MIBC subtypes [10-13]. However, the diversity of their subtype sets, so far, has impeded their clinical application.

Based on the transcriptomic profiles of 1750 MIBCs from 16 published datasets, two additional cohorts, and a network-based analysis of six independent MIBC classification systems, a consensus set of six molecular classes has been identified by a single-sample transcriptomic classifier [9]. The six molecular classes included: the basal/squamous class (Ba/Sq), accounting for 35\% of all MIBC; the luminal/papillary class (LumP), accounting for $24 \%$; the luminal unstable class (LumU), accounting for $15 \%$; the stroma-rich class, accounting for $15 \%$; the luminal non-specified class (LumNS), accounting for $8 \%$; and the neuroendocrine (NE)-like class, accounting for 3\% [9].

An association of some of these classes with The Cancer Genome Atlas (TCGA) PanCancer clusters has been observed between the $\mathrm{Ba} / \mathrm{Sq}$ and the Squamous cell carcinoma (C27: Pan-SCC pan-cancer cluster) $(p<0.001)$, and the stroma-rich class with the stromadriven class (C20: Mixed stromal/immune) $(p<0.001)$ [9]. 
The six molecular classes differ by their underlying oncogenic mechanisms, infiltration by immune and stromal cells, histological and clinical characteristics, and survival outcomes.

Regarding their prognostic value, based on 872 patients, and taking the LumP class as the reference for class-based survival, the LumNS (hazard ratio [HR] 1.07, 95\% confidence interval [CI] 0.63-1.82) and stroma-rich classes (HR 0.98, 95\% CI 0.65-1.49) showed a similar prognosis to the LumP class; the LumU class did not have significantly inferior overall survival (OS) (HR 1.49,95\% CI 0.93-2.39), the Ba/Sq class had a significantly poorer prognosis (HR 1.83, 95\% CI 1.30-2.58, $p<0.001$ ), and the NE-like class had the worst prognosis (HR 2.34, 95\% CI 1.09-5.05, $p<0.03$ ) [9].

In addition to common urothelial differentiation signatures, like the PPARG/GATA3/ FOXA1-related Lund urothelial ones, the luminal classes may selectively bear gene alterations which are potentially relevant as drug targets, such as the FGFR3 in the LumP, and the TP53, high TMB and ERCC2 — which are related to higher cell cycle activity and genomic instability-in the LumU. Similarly, the Ba/Sq was enriched in cytotoxic lymphocytes (CTL) and NK, alongside EGFR mutations, the Stroma-rich in T- and B-Cells, and the NE-like in TP53 and RB1 alterations [9].

Concerning treatment responses, an enrichment in responders to atezolizumab was observed among LumNS, LumU and NE-like [9]. However, previous discordant results from the TCGA and different ICIs $[11,14]$ indicate the need for prospective validation.

The molecular classification might be used for prognostication to assist treatment evaluation, and, at the same time, for a more productive collection of clinical information. However, prospective validation is warranted because the use of such classification is only supported by retrospective clinical data lacking the complete patients' treatment history. Furthermore, it might represent a robust framework enabling the testing and validation of predictive biomarkers in future prospective clinical trials, including basket trials, based on similarities with other cancer molecular subtypes according to the PanCancer Atlas, such as the $\mathrm{Ba} / \mathrm{Sq}$ and Lum.

On the other hand, an integrative multi-omics analysis has recently been performed to better characterize Non-Invasive Muscle Bladder Cancer (NIMBC) [15]. In this study, the authors identified four molecular classes reflecting the behaviour and aggressiveness of UC, driving the implementation of biomarkers with predictive and prognostic value [15].

The genomic landscape of NMIBC showed complex genomic patterns, with activating mutations in FGFR3 and PIK3CA, such as chromosome 9 deletions in early disease [16,17]. The NMIBCs were also subdivided into different progression risk groups based on mutations in FGFR3, the methylation of GATA2 and copy number alterations (CNAs). All of these data could provide new molecular therapeutic targets [16,17].

\subsection{Tumour Mutational Burden (TMB)}

TMB can be defined as the total number of non-synonymous mutations per coding area of a tumour genome [18]. These mutations can be transcribed and translated to generate neoantigens displayed on the cell surface; T-lymphocytes can recognise some of these neoantigens and promote the apoptosis of tumour cells [18]. Tumours with a high mutational load are more likely to express neoantigens, and to induce a strong immune reaction [19]. Several studies have demonstrated an association between a high TMB and the response to immunotherapy in different locally advanced or metastatic solid tumour types [20].

In June 2020, the FDA approved pembrolizumab for the treatment of adult and paediatric patients with unresectable or metastatic solid cancers and a high TMB [>10 mutations / megabase (mut/Mb)] [21]. This approval was based on the efficacy data from the phase II KEYNOTE-158 trial, which demonstrated an association between a high TMB and the tumour response to immunotherapy, with a durable response ( $>2$ years) rarely being observed in heavily pre-treated metastatic cancers [22]. 
UC, along with melanoma and lung cancer, is characterized by a high number of somatic mutations and, therefore, a significant genomic instability [8]. The exploratory analyses of the phase II IMvigor210 trial included the quantification of the mutational load and a correlation with the clinical outcomes [23]. As expected, the TMB was significantly higher in patients who responded to atezolizumab than in non-responders. Moreover, patients with a higher mutational load had significantly longer overall survival than patients with a lower load [23].

However, the TMB status alone was not able to stratify the patients according to the survival benefit. In this regard, exploratory analyses of the JAVELIN Bladder 100 trial demonstrated that some DNA mutational signatures, involving certain base pair alterations, were associated with a survival benefit from avelumab, while other mutations were not [24] This suggests that the type and the location of mutations may influence the predictive role of TMB assessment more accurately than the degree of the mutational load.

The predictive value of TMB for the pathological response to immunotherapy has also been explored in the neoadjuvant setting $[25,26]$. In patients with MIBC, a high TMB was generally observed in responders versus non-responders to neoadjuvant pembrolizumab, irrespective of the histological subtypes [27].

The predictive role of combining TMB with PD-L1 was also investigated. Patients with high TMB and PD-L1-positive tumours were more likely to derive a survival benefit from avelumab maintenance therapy [24]. Similar findings were observed in the randomised phase III IMvigor130 study [28]. The association of high PD-L-1 (>5\% of immune cells) and a high TMB (>10 mut/MB) was associated with improved OS in the atezolizumab monotherapy arm, as compared to the chemotherapy arm [28]. Nevertheless, similar outcomes were not seen with the combination of atezolizumab and chemotherapy compared to the chemotherapy alone, suggesting a potentially distinct biology driving the benefit from atezolizumab and its combination with chemotherapy, and eventually highlighting the predictive inconsistency of this biomarker combination [28].

As for other tumour types, many factors hinder the clinical application of TMB as a biomarker, including the variability and the lack of a validated cut-off, a clear prognostic value, the differences related to the sequencing platforms used for its assessment, and the high scoring failure rate due to the quantity and quality of tumour tissue analysed [29]. As an example for the mUC, in the IMvigor210 study, the cut-off of the TMB varied between the two different cohorts of cisplatin-ineligible $\mathrm{mUC}$ treated with first-line atezolizumab and the platinum-treated patients [23]. Moreover, a high tumour mutational load may not be a specific biomarker for immunotherapy, as it has also been associated with the tumour response to neoadjuvant chemotherapy $[30,31]$.

\subsection{Mulecular Signatures}

The increasing interest in tumour molecular features and new omics technologies has led to the discovery of different molecular signatures. These involve genes, messenger ribonucleic acids (mRNAs) and proteins which are studied as biomarkers to better predict clinical outcomes, or to better understand the cancerogenesis process [32,33].

Furthermore, because the TMB and/or the PD-L1 expression did not precisely identify patients who were more likely to derive benefit from immunotherapy [34,35], the assessment of tumour-related or immune-related gene signatures was actively investigated.

The DNA and RNA sequencing analyses of the IMvigor130 trial investigated the apolipoprotein B editing catalytic polypeptide (APOBEC) signature [28]. The APOBEC enzymes are a family of cytidine deaminases involved in the DNA repair processes, and are responsible for a mutation signature $(\mathrm{TCW}>\mathrm{T} / \mathrm{G}$ ) frequently observed in MIBCs $[36,37]$. Patients with a high APOBEC mutational signature had a longer survival, whether in the atezolizumab monotherapy or the combination arm with chemotherapy compared to chemotherapy alone, whereas a high TGF $\beta$ signature predicted a worse OS with the immunotherapy alone [28]. 
RNA-based immune-gene expression profiling has the advantage of providing information from many cancer cells and immune cells, identifying more accurately the inflammatory status. The Checkmate-275 study investigated an interferon-gamma (IFN- $\gamma$ ) expression signature, and found a significant correlation with the response to nivolumab in the metastatic setting [38].

At the ESMO 2020 meeting, an exploratory analysis of the Javelin Bladder 100 study on tumour biomarkers was presented. While neither PD-L1 and TMB alone nor in combination predicted the response to immunotherapy and survival benefit, the expression of the immune-related genes of both the innate and adaptive immune system (i.e., CD8, IFNG, LAG3, TIGIT and CXCL9) and the number of alleles encoding high-affinity Fc gamma receptor variants predicted the survival benefit from avelumab first-line maintenance [24]. The application of the T-cell-inflamed and JAVELIN-Immuno signatures seemed to correlate with the treatment response with HRs of 0.55 and 0.49 , respectively. Furthermore, the JAVELIN-Immuno high signature showed enrichment in some signalling pathways (Notch, Hedgehog, TGFbeta) which were likely to have an increased antitumour response to immunotherapy [24].

In the PURE-01 study, investigating the efficacy of pembrolizumab as a neoadjuvant therapy, a T-cell-inflamed signature was able to identify those patients who achieved pathological T0 downstaging. In a subsequent analysis, other RNA-based immune signatures were evaluated for their association with $\mathrm{pCR}$ and a high Immune190 signature, as well as hallmark signatures for interferon gamma and interferon-alpha, which were significantly associated with pCR and progression-free survival (PFS) after pembrolizumab in the PURE01 study [27]. Similarly, a correlation between the tumour response to atezolizumab and the transcriptional signature of eight genes (IFNG, CXCL9, CD8A, GZMA, GZMB, CXCL10, PRF1 and TBX21) representing interferon signalling, and the presence of CD8+ effector T cells, namely the tGE8, was reported within the ABACUS neoadjuvant study [39].

Moreover, a strong immune-mediated adaptive resistance was observed in nonresponding tumours, suggesting the investigation of ICI combinations to counteract the expression of negative regulators of the immune response [40].

The BISCAY study combined durvalumab (anti-PD-L1) with different targeted therapies depending on tumour gene alterations determined by NGS [41]. Despite the overall negative results, this study suggested a negative predictive role for the FGFR expression with regards to immunotherapy. In fact, FGFR-mutated tumours did not have a high expression of immune-active T-cell signatures, and the addition of durvalumab did not result in enhanced activity from the targeting agent only [9,41].

Although the above data look promising, there is a need to standardize molecular assays and find a molecular panel which is applicable to daily clinical practice.

\section{4. ctDNA}

The sequencing of the tumour fraction of the cell-free DNA (ctDNA) is an emerging and sensitive method to detect residual disease, anticipate relapse, and monitor the therapeutic efficacy in patients with several cancer types [42,43]. Furthermore, it provides a basis for clinical studies evaluating early therapeutic interventions [42,43].

In UCs, proof-of-concept data documented that ctDNA is detectable in plasma and urine, and could be a prognostic factor [44,45].

Vandekerkhove et al. demonstrated that ctDNA profiling may also identify putative biomarkers for therapy response in bladder cancer (such as FGFR3, ERCC2, ERBB2 and $\mathrm{TMB}$ ), and represents a cost-effective and minimally invasive method for their identification and patient stratification [46]. Furthermore, the serial monitoring of ctDNA can optimize the use of therapies, as ctDNA fractions are expected to decrease in patients responding to treatment [46].

In a longitudinal analysis, the presence of ctDNA-assessed by whole-exome sequencing (WES) in 68 patients with localised advanced bladder cancer at diagnosis-during chemotherapy, before and after cystectomy and during surveillance, resulted in being 
highly prognostic at diagnosis (HR 29.1) [47]. The presence of ctDNA identified all of the patients with metastatic relapse (with $100 \%$ sensitivity and $98 \%$ specificity), with a median of 96 days of diagnostic anticipation compared to the radiographic imaging [47]. Furthermore, the dynamics of ctDNA during chemotherapy, for those patients with positive ctDNA before or during the treatment, were associated with disease recurrence. It is worth noting that pathological downstaging, including related mutational signatures, was not associated with disease recurrence [47].

A post-surgical ctDNA detection was also associated with a higher risk for recurrence and death in the randomised phase III IMvigor010 study with adjuvant atezolizumab versus observation following cystectomy for patients with MIBC [48]. Moreover, the presence of ctDNA was predictive, as it was able to identify the patients who were likely to benefit from adjuvant atezolizumab. The IMvigor010 study did not meet his primary endpoint of disease-free survival (DFS) in the overall population of 809 enrolled patients [48]. The ctDNA was assessed by WES at a median of 11 weeks post-cystectomy in 581 patients with evaluable samples, comprising $72 \%$ of the intent-to-treat population of the IMvigor010 study. While the detection of ctDNA (in 214 patients, 37\%) was associated with worse DFS and OS compared to the absence of ctDNA (in 367 patients, 63\%), a significant difference in DFS (HR 0.58, 95\% CI 0.43-0.79) and OS (0.59, 95\% CI 0.41-0.86, $p=0.0059)$ was observed in favour of the patients with detectable ctDNA treated with atezolizumab compared to the observational arm. Furthermore, in patients with the presence of ctDNA, the rate of ctDNA clearance from cycle 1 to cycle 3 was significantly higher in the atezolizumab arm versus the observational one, with ctDNA clearance rates of $18.2 \%$ and $3.8 \%$, respectively $(p=0.0048)[48]$.

\subsection{Programmed Death Ligand-1 (PD-L1)}

In the first-line treatment of $\mathrm{MUC}$, a high PD-L1 combined positive score (CPS) of $\geq 10 \%$, defined as the percentage of tumour cells (TC) and immune cells (IC)/the total tumour cells given by the 22C3 Dako assay, was associated with a prolonged median OS (mOS) in patients ineligible for cisplatin treatment with first-line pembrolizumab in the single-arm phase II KEYNOTE 052 study. The mOS was 18.3 versus 9 months in patients with PD-L1 CPS $\geq 10 \%$ and $<10 \%$, respectively, and it was 11.3 months in the overall population [49]. As the KEYNOTE 052 was not a controlled phase III study, a favourable prognostic value only for the high PD-L1 expression could not be rule out. Indeed, in the following KEYNOTE 361, IMvigor130 and Danube phase III randomised trials, the anti-PD1/PD-L1 agents either alone or in combination with chemotherapy were not superior to the chemotherapy according to OS in patients with high PD-L1 tumours, as well as in the overall population [50-52]. Only in the Danube trial did the combination of the anti-PD-L1 inhibitor durvalumab and anti-CTLA4 tremelimumab show a superior OS compared to chemotherapy in patients with high PD-L1. Therefore, the predictive value of high PD-L1 remains uncertain [52]. In contrast, a decreased survival with first-line pembrolizumab or atezolizumab compared to platinum-based chemotherapy was reported by the KEYNOTE 361 and IMvigor130 phase III trials for patients with low PD-L1 tumour expression, suggesting a negative predictive value for low PD-L1 expression [50,51]. A low PD-L1 expression was defined in the KEYNOTE 361 and IMvigor130 studies as a CPS $<10 \%$ or positive IC $<5 \%$ by the immunohistochemistry (IHC) $22 \mathrm{C} 3$ pharmDx and SP142 Ventana assays, respectively [50,51].

In the maintenance setting of $\mathrm{mUC}$, following first-line chemotherapy, the Javelin-100 phase III trial showed an advantage in OS from the anti-PD-L1 avelumab compared to the best supportive care irrespective of the positive PD-L1 expression, which was assessed by a SP263 Ventana assay and classified as positive if at least one of the following three criteria were met: at least $25 \%$ TC staining for PD-L1, at least 25\% IC staining for PD-L1 if more than $1 \%$ of the tumour area contained IC, or $100 \%$ ICs staining for PD-L1 if no more than $1 \%$ of the tumour area contained ICs [53]. 
In the adjuvant setting of UC, the IMvigor 010 with the anti-PD-L1 atezolizumab did not show a significant advantage in DFS compared to observation either in patients with positive PD-L1 tumours IC according to the SP142 Ventana assay, or in the overall population [54], while the Checkmate274 showed a significant DFS advantage in favour of nivolumab versus observation in the intention-to-treat population with a better $\mathrm{HR}$ in patients with a PD-L1 expression $\geq 1 \%$ (HR 0.55 vs. 0.70 for the overall population), as assessed on TC by a PD-L1 IHC 28-8 pharmDx assay [55].

In the second-line of $\mathrm{mUC}$, in the IMvigor 211 phase III study with anti-PD-L1 atezolizumab compared to chemotherapy, the OS was not significantly different in patients with a high PD-L1 defined by IC $2 / 3$ (or $\geq 5 \% / 10 \%$ of PD-L1 positive IC according to a SP142 Ventana assay) [56]. In contrast, in the KEYNOTE 045 study, a significant difference in OS was observed in favour of the anti-PD-1 pembrolizumab versus chemotherapy in patients with high PD-L1 tumours defined as CPS according the 22C3 Dako assay [57]. Although possible differences in efficacy between the anti-PD1 and anti-PD-L1 agents cannot completely be ruled out [58], plausible explanations may rely on the different tests and scores used to assess the PD-L1 expression, as well as on the tumoural site and timing of the biopsy in respect to the disease history. In this regard, it is noteworthy that the mOS duration in the high PD-L1 subgroup of patients differed between those two trials despite the similar populations enrolled and the mOS observed in the overall population of the chemotherapy control arm (of 8.4 and 7.3 months, for the IMvigor211 and the Keynote-045 study, respectively) [56,57]. In the KEYNOTE 045 study, the mOS of patients with high CPS $(\geq 10 \%)$ treated with pembrolizumab was of 8.0 months, which was significantly longer than 5.2 months with chemotherapy ( $p=0.0048$ ) [57]; on the other hand, in the IMvigor211 study, the patients with high IC 2/3 had an mOS of 11.1 months with atezolizumab, which was not significantly longer than 10.6 months with chemotherapy $(p=0.41)$ [56]. The OS difference seen in the chemotherapy control arms of these two studies, with a different definition of high PD-L1 tumours, might suggest a positive prognostic value which is marginally predictive for the high PD-L1 by the IC $2 / 3$, and a negative prognostic - although predictive - value by the CPS.

In the neoadjuvant setting, only phase II studies are currently available. However, the Pure-01 study demonstrated the dynamic characteristic of the PD-L1 by showing its significantly increased expression as CPS following three administrations of the anti-PD1 pembrolizumab [40].

In conclusion, the current evidence on the prognostic and predictive value of PD-L1 expression is limited by the different diagnostic assays used in the clinical trials for each anti-PD1 or anti-PD-L1 agent, and remains inconclusive. PD-L1 may have a prognostic role, the value of which may also change depending on the type of tumour cells scored (i.e., negative if CPS, or positive if IC), and may be predictive only for the low expression.

The molecular predictive and prognostic factors in UCs are summarized in Table 1.

Table 1. Molecular factors and their prognostic and predictive value in UC patients, with a particular focus on ICIs.

\begin{tabular}{|c|c|c|c|}
\hline Category & Description & $\begin{array}{c}\text { Prognostic and Predictive Value } \\
\text { in UC }\end{array}$ & Notes \\
\hline Molecular classes & $\begin{array}{c}6 \text { molecular (transcriptomic) } \\
\text { classes based on a consensus } \\
\text { of MIBC: } \\
\text { Squamous (Ba/Sq)-35\%; } \\
\text { luminal/papillary (LumP), } \\
\text { 24\%; luminal unstable } \\
\text { (LumU), 15\%; stroma-rich, } \\
15 \% \text {; luminal non-specified } \\
\text { (LumNS), 8\%; neuroendocrine } \\
\text { (NE)-like, 3\% [9]. }\end{array}$ & $\begin{array}{l}\mathrm{Ba} / \mathrm{Sq} \text { is associated with shorter OS, } \\
\text { NE-like is associated with worse } \\
\text { prognosis (LumP as reference) [9]. } \\
\text { LUmNS, LumU, NE-like are more } \\
\text { responsive to ICIs [9]. }\end{array}$ & $\begin{array}{l}\text { Need for } \\
\text { prospective validation }\end{array}$ \\
\hline
\end{tabular}


Table 1. Cont.

\begin{tabular}{|c|c|c|c|}
\hline Category & Description & $\begin{array}{c}\text { Prognostic and Predictive Value } \\
\text { in UC }\end{array}$ & Notes \\
\hline TMB & $\begin{array}{c}\text { Total number of } \\
\text { non-synonymous mutations } \\
\text { per coding area of a tumour } \\
\text { genome. UC is characterized } \\
\text { by high values of TMB } \\
\text { compared to other } \\
\text { tumours [23]. }\end{array}$ & $\begin{array}{l}\text { High TMB predicts OS benefit from } \\
\text { avelumab maintenance therapy [23] } \\
\text { and improved OS with atezolizumab } \\
\text { when compared to CT [28]. } \\
\text { TMB was higher in responder to } \\
\text { neoadjuvant pembrolizumab [27]. }\end{array}$ & $\begin{array}{l}\text { Issues: variability, lack of a } \\
\text { validated cut-off, differences } \\
\text { related to the } \\
\text { sequencing platforms }\end{array}$ \\
\hline Molecular signatures & $\begin{array}{l}\text { Study of involved genes } \\
\text { (DNA sequencing), messenger } \\
\text { ribonucleic acids (mRNAs) } \\
\text { (RNA sequencing), and } \\
\text { proteins (transcriptome) in } \\
\text { tumor samples. }\end{array}$ & $\begin{array}{c}\text { APOBEC mutational signature } \\
\text { predicts OS benefit with atezolizumab } \\
\pm \text { CT compared to CT alone [28]. } \\
\text { TGF- } \beta \text { signature predicts worse OS } \\
\text { with ICIs [28]. } \\
\text { IFN- } \gamma \text { signature correlates with } \\
\text { response to nivolumab [38]. } \\
\text { JAVELIN -Immuno high signature } \\
\text { correlates with increased responses to } \\
\text { ICIs [24]. } \\
\text { Transcriptional signature of eight } \\
\text { genes (IFNG, CXCL9, CD8A, GZMA, } \\
\text { GZMB, CXCL10, PRF1 and TBX21) } \\
\text { correlates with response to } \\
\text { atezolizumab [39]. } \\
\text { FGFR mutations predict low response } \\
\text { to durvalumab [41]. }\end{array}$ & $\begin{array}{c}\text { Need to standardize } \\
\text { molecular assays and find a } \\
\text { molecular panel applicable to } \\
\text { daily clinical practice }\end{array}$ \\
\hline ctDNA & $\begin{array}{l}\text { Quantitative and qualitative } \\
\text { analysis of circulating tumoral } \\
\text { DNA detected on } \\
\text { blood samples. }\end{array}$ & $\begin{array}{l}\text { ctDNA detection is associated with } \\
\text { worse prognosis in early stages and } \\
\text { could identify metastatic relapses } \\
\text { before imaging [47]. } \\
\text { ctDNA detection is predictive for } \\
\text { adjuvant atezolizumab } \\
\text { (both DFS and OS) [48]. } \\
\text { ctDNA profiling may be predictive } \\
\text { for response to specific therapies [46]. }\end{array}$ & \\
\hline PD-L1 & $\begin{array}{l}\text { Expression of the ligand of } \\
\text { PD1 receptor has been widely } \\
\text { studied as predictive } \\
\text { biomarker of response to } \\
\text { anti-PD1 and anti-PD-L1 } \\
\text { therapies across } \\
\text { human cancers. }\end{array}$ & $\begin{array}{l}\text { Possibly predictive for anti-PD1 and } \\
\text { anti-PD-L1 agents used in UC } \\
\text { patients as adjuvant [54], } \\
\text { first-line [49], maintenance after } \\
\text { first-line [53] and second-line } \\
\text { therapy [56]. }\end{array}$ & $\begin{array}{l}\text { Issues: different diagnostic } \\
\text { assays used in clinical trials } \\
\text { for each anti-PD1 or } \\
\text { anti-PD-L1 agent, discordant } \\
\text { efficacy of these agents } \\
\text { between studies }\end{array}$ \\
\hline
\end{tabular}

Abbreviations: UC, urothelial carcinoma; ICIs, immune checkpoint inhibitors; TMB, tumor mutational burden; OS, overall survival; $\mathrm{CT}$, chemotherapy; ctDNA, circulating tumor DNA.

\section{Clinical Factors}

\subsection{Patient's Characteristics}

Several clinical factors have been reported to be prognostic in patients with mUC treated with chemotherapy. The most important ones include performance status (PS), metastatic sites, haemoglobin levels, and time from prior chemotherapy. Bajorin et al. showed that, in untreated patients, a poor Karnofsky Performance Status (KPS) $<80 \%$ and the presence of visceral (liver, lung, and bone) metastases were independent prognostic factors associated with a worse OS [59]. Bellmunt et al. reported that a poor Eastern Cooperative Oncology Group (ECOG) PS $\geq 2$, low haemoglobin levels $(<10 \mathrm{~g} / \mathrm{dL})$ and the presence of liver metastasis were independent poor prognostic factors in patients who failed platinum-based chemotherapy [60]. Moreover, a shorter time from prior chemotherapy 
( $<3$ months) has been reported to enhance the prognostic classification of patients receiving second-line therapy [61].

The survival benefit of immunotherapy in both untreated and pretreated patients with $\mathrm{mUC}$ has been observed regardless of all of those clinical factors, confirming their prognostic but not predictive value, in many retrospective analyses [62-70] and subgroup and post-hoc analyses of prospective randomised trials [71,72].

\subsection{Concomitant Medications}

Several retrospective analyses and meta-analyses have recently been reported in the literature about the impact of concomitant medications on the clinical outcomes of patients with cancer treated with ICIs [73-78]. These studies mainly included patients with nonsmall cell lung cancer (NSCLC), melanoma or renal cell carcinoma (RCC). Commonly used drugs in clinical practice-such as corticosteroids, antibiotics and proton pump inhibitors (PPIs) - have been reported to negatively affect the activity of immunotherapy through immune-modulatory effects. In fact, these drugs may induce a detrimental effect on the immune system and gut microbiota, which is a well-known regulator of immune homeostasis [79]. A drug-based prognostic score developed by Buti et al.-including the cumulative exposure to high-dose steroid therapy (a dose of $\geq 10 \mathrm{mg}$ prednisoneequivalents per day), antibiotics and PPIs—can help to stratify patients treated with ICIs in routine practice and clinical trials [73].

The post-hoc analyses of the single-arm phase II IMvigor210 trial and the randomised phase III IMvigor211 trial confirmed the negative predictive role of PPI and antibiotic use in patients with mUC treated with ICI, but not in the case of treatment with chemotherapy $[80,81]$.

\subsection{Inflammatory Indices}

An inflammatory condition in patients with cancer has been associated with worse outcomes and a lower therapeutic response across different tumour types [82]. Inflammatory indices from peripheral blood have been investigated as potential biomarkers in different tumours, settings and therapies [83-85], including patients with UC treated with surgery or chemotherapy [64,86-88].

As far as ICIs are concerned, inflammatory indices have been mostly studied in patients with advanced NSCLC and melanoma [89,90], while fewer and smaller studies have been conducted in patients treated with ICIs for genitourinary tumours, including UC $[62,63,65,69,70,91-97]$. The inflammatory indices most commonly studied in patients with UC treated with ICIs include the neutrophil-to-lymphocyte ratio (NLR), baseline platelet-to-lymphocyte ratio (PLR), lymphocyte-to-monocyte ratio (LMR), lactate dehydrogenase (LDH), C-reactive protein (CRP) and albumin. High levels of NLR, PLR, LDH and CRP, and low levels of albumin have been correlated with worse survival and efficacy outcomes, either as single parameters or within combined prognostic scores [62,63,65,69,70,92-98].

\subsection{Combined Prognostic Tools}

Inflammatory indices from peripheral blood have been investigated in combination with other clinical prognostic factors within prognostic models for risk-stratification in several cancer types treated with ICIs, especially the NSCLC $[91,98-100]$. The interest in prognostic models has also recently been increasing for genitourinary tumours, including RCC [101-103] and UC [63,65,68,95-97,104].

In patients with mUC treated with ICIs, the most frequently included factors in prognostic models are inflammatory indices (such as NLR, C-reactive protein and albumin) and pretreatment clinical parameters (i.e., the PS and metastatic site) $[63,65,68,95-97,104-106]$. The molecular factors included in the prognostic scores were PD-L1 expression and genomic parameters (e.g., single-nucleotide variants) [96,104]. 
Most of these analyses are derived from retrospective studies, except for the two prognostic scores developed by Fornarini et al. and Sonpavde et al., and the machine learning (ML) model developed by Abuhelwa et al. [104-106]. The two prognostic models were developed by the retrospective analysis of the phase IIIb SAUL trial [104] and the two phase I/II trials [105], both evaluating second-line ICI monotherapy. The ML model was built using the atezolizumab cohort of the IMvigor210 trial as the training cohort, and the IMvigor211 trial population as the external validation [106].

Most of these prognostic models (Table 2) need external validation with prospective studies before being incorporated into clinical practice; only one of them has shown a predictive value for immunotherapy but not for chemotherapy in a retrospective analysis [96].

Table 2. Clinical factors and their prognostic and predictive value in UC patients, with a particular focus on ICIs.

\begin{tabular}{|c|c|c|}
\hline Category & Description & Prognostic and Predictive Value in UC \\
\hline Patient's characteristics & $\begin{array}{l}\text { Performance status (PS), metastatic sites, } \\
\text { haemoglobin levels are prognostic factors } \\
\text { in human cancer. }\end{array}$ & $\begin{array}{c}\text { Karnofsky PS }<80 \% \text {, ECOG PS } \geq 2 \text {, low } \\
\text { haemoglobin levels and the presence of visceral } \\
\text { metastases are associated with worse OS in mUC } \\
\text { patients treated with CT }[59,61] \text {. } \\
\text { Prognostic but not predictive in mUC patients } \\
\text { treated with ICIs [62-72]. }\end{array}$ \\
\hline Concomitant medications & $\begin{array}{l}\text { Commonly used drugs in clinical practice } \\
\text { may affect clinical outcomes of cancer } \\
\text { patients treated with ICIs. }\end{array}$ & $\begin{array}{l}\text { Use of antibiotics and PPIs have a negative } \\
\text { predictive role in mUC patients treated with ICIs } \\
\text { but not in those treated with CT }[80,81] .\end{array}$ \\
\hline Inflammatory indices & $\begin{array}{l}\text { Inflammatory indices, like NLR, CMP } \\
\text { and albumin, have been investigated in } \\
\text { several human cancer types as prognostic } \\
\text { tools, especially regarding ICIs. }\end{array}$ & $\begin{array}{c}\text { High levels of NLR, PLR, LDH, CRP and low } \\
\text { levels of albumin have been correlated with worse } \\
\text { survival and efficacy outcomes in mUC } \\
\text { patients }[62-64,70,92-98] .\end{array}$ \\
\hline Combined prognostic tools & $\begin{array}{l}\text { Combinations of inflammatory indices } \\
\text { and clinical factors have been } \\
\text { investigated in several human cancer } \\
\text { types as prognostic tools, especially } \\
\text { regarding ICIs. }\end{array}$ & $\begin{array}{l}\text { Two prognostic models were developed in } \\
\text { second-line ICIs mono-therapy [104,105]. } \\
\text { A machine learning model was built from } \\
\text { IMvigor210 atezolizumab arm and validated in } \\
\text { IMvigor211 atezolizumab arm [106]. }\end{array}$ \\
\hline
\end{tabular}

Abbreviations: UC, urothelial carcinoma; mUC, metastatic urothelial carcinoma; ICIs, immune checkpoint inhibitors; OS, overall survival; CT, chemotherapy; PPIs, proton pump inhibitors; NLR, neutrophil-to-lymphocyte ratio; PLR, platelet-to-lymphocyte ratio; LMR, lymphocyte-to-monocyte ratio; LDH, lactate dehydrogenase; CRP, C-reactive protein (CRP).

\section{Radiomics}

Due to the growing need to identify useful biomarkers to select the patients who are most likely to benefit from ICIs, the quantitative analysis of imaging features by artificial intelligence algorithms, namely radiomics, has recently been investigated as a possible surrogate marker to predict the outcome of patients treated with immunotherapy [107,108]. Radiomics has been reported as a promising approach to predict the response and survival outcomes in patients with NSCLC and melanoma receiving ICIs [109,110]. Three retrospective analyses investigated radiomics from baseline contrast-enhanced computed tomography $(\mathrm{CT})$ images in patients with mUC receiving anti-PDL1 or anti-PD1 monotherapy [111-113].

Artificial intelligence algorithms may also allow us to combine the information obtained by the image features with other clinical and laboratory prognostic factors, thus increasing the diagnostic accuracy of predictive models [112,113].

Artificial intelligence and deep machine learning-based models may provide helpful decision tools to clinicians for the selection of patients for ICIs in the near future. However, none of these radiomics-based models have been assessed in patients with UC treated with chemotherapy yet; further studies on larger populations and external validation are still needed to confirm their predictive value. 


\section{Conclusions}

In the current era, in which ICIs have been tested for several tumour types, it is crucial to identify prognostic and predictive biomarkers or models which are able to select UC patients who will benefit from ICIs, especially as novel therapeutic agents could soon become available in clinical practice for the treatment of UC. In addition, adjuvant ICIs have recently shown a benefit in terms of disease-free survival in patients with radically resected muscle-invasive urothelial carcinoma [112]. With more follow-up, a survival benefit is awaited, opening new methods for biomarker identification even in this setting.

By reviewing the available evidence and attempting a classification of clinical and tumour factors according to levels of evidence and grades of recommendation (see Table 3), both a prognostic and a predictive value is currently suggested for ctDNA, while only a prognostic relevance seems to apply to concomitant medications and patient's characteristics.

Table 3. Prognostic and predictive values of tumour and clinical factors for their impact on the response and survival outcomes in mUC treated with ICIs.

\begin{tabular}{|c|c|c|c|c|c|c|}
\hline \multirow{2}{*}{$\begin{array}{c}\text { Variable } \\
\text { Parameter }\end{array}$} & \multicolumn{3}{|c|}{ Prognostic } & \multicolumn{3}{|c|}{ Predictive } \\
\hline & $\begin{array}{l}\text { Clinical } \\
\text { Value }\end{array}$ & $\begin{array}{l}\text { Strenght of } \\
\text { Evidence }\end{array}$ & $\begin{array}{l}\text { Outcome } \\
\text { Variable }\end{array}$ & $\begin{array}{l}\text { Clinical } \\
\text { Value }\end{array}$ & $\begin{array}{l}\text { Strenght of } \\
\text { Evidence }\end{array}$ & $\begin{array}{l}\text { Outcome } \\
\text { Variable }\end{array}$ \\
\hline \multicolumn{7}{|c|}{ Tumour molecular factors } \\
\hline Molecular classes for MIBC & & IV, B & PFS, OS & & IV, B & PFS, OS \\
\hline TMB & & IV, C & ORR, PFS, OS & & $\mathrm{I}, \mathrm{C}$ & ORR, PFS, OS \\
\hline Mutational signatures ${ }^{1}$ & & IV, C & ORR, PFS, OS & & $\mathrm{I}, \mathrm{C}$ & ORR, PFS, OS \\
\hline ctDNA & & II, A & DFS, OS & & II, A & DFS, OS \\
\hline PD-L1 & & $\mathrm{I}, \mathrm{C}$ & DFS, PFS, OS & & I, $B^{2}$ & DFS, PFS, OS \\
\hline \multicolumn{7}{|c|}{ Clinical factors } \\
\hline Patient's characteristics ${ }^{3}$ & & $\mathrm{I}, \mathrm{A}$ & ORR, PFS, OS & & $\mathrm{I}, \mathrm{A}$ & ORR, PFS, OS \\
\hline Concomitant medications 4 & & $\mathrm{I}, \mathrm{A}$ & ORR, PFS, OS & & I, B & ORR, PFS, OS \\
\hline Inflammatory indices 5 & & IV, A & ORR, PFS, OS & & IV, A & ORR, PFS, OS \\
\hline Combined tools ${ }^{6}$ & & III, B & ORR, PFS, OS & & IV, C & ORR, PFS, OS \\
\hline \multicolumn{7}{|c|}{ Radiomics } \\
\hline Radiomics-based models ${ }^{7}$ & & IV, B & ORR, PFS, OS & & NI & NI \\
\hline
\end{tabular}

PFS, progress-free survival; OS, overall survival; ORR, overall response rate; DFS, disease-free survival; NI, not investigated. ${ }^{1}$ DNA and RNA signatures such as the APOBEC, TGFbeta, IFN- $\gamma$ and IFN-alpha; immune-related signatures such as the JAVELIN-Immuno or Immune190. ${ }^{2}$ Evidence was limited due to its low expression. ${ }^{3}$ Poor PS, visceral metastases, mainly liver metastases, low hemoglobin levels, and a shorter time from prior chemotherapy ( $<3$ months). ${ }^{4}$ High-dose steroid therapy, antibiotics and PPIs. ${ }^{5}$ Inflammatory indices from peripheral blood, such as ratios of immune system cells (e.g., NLR) or LDH. ${ }^{6}$ Combination of inflammatory indices and clinical parameters. ${ }^{7}$ Radiomic features with/without clinical factors. Green circle: clinically useful. Yellow circle: uncertain clinical

usefulness. Red circle: not clinically useful. The strength of evidence was adapted from the Infectious Diseases Society of AmericaUnited States Public Health Service Grading System [7]. Levels of evidence: I, evidence from at least one large randomised, controlled trial of good methodological quality (low potential for bias) or meta-analyses of well-conducted randomised trials without heterogeneity; II, small randomised trials or large randomised trials with a suspicion of bias (lower methodological quality), or meta-analyses of such trials or of trials with demonstrated heterogeneity; III, prospective cohort studies; IV, retrospective cohort studies or case-control studies; $\mathrm{V}$, studies without a control group, case reports, or expert opinions. Grades of recommendation: A, strong evidence for efficacy with a substantial clinical benefit, strongly recommended; B, strong or moderate evidence for efficacy, but with a limited clinical benefit, generally recommended; C, insufficient evidence for efficacy or benefit does not outweigh the risk or the disadvantages (adverse events, costs, etc.), optional; D, moderate evidence against efficacy or for adverse outcomes, generally not recommended; E, strong evidence against efficacy or for adverse outcomes, never recommended.

We think this information may be helpful to clinically assess mUCs patients who are considered for treatment with ICIs, and could also drive further prospective research on these biomarkers, either as single factors or within combined prognostic models implemented by artificial intelligence algorithms. 
Author Contributions: Conceptualization, S.E.R., G.L.B. and G.F.; methodology, S.E.R. and G.L.B.; writing-original draft preparation, S.E.R., G.L.B., V.M., A.D., F.F. and G.F.; writing-review and editing, S.E.R., G.L.B., E.F.G., U.D.G., R.C., P.R. and M.B.; supervision, S.E.R., G.L.B. and G.F. All authors have read and agreed to the published version of the manuscript.

Funding: This research received no external funding.

Acknowledgments: S.E.R. and G.F. would like to thank the Italian Ministry of Health (Ricerca Corrente 2018-2021 grants), which financially supports their current research focused on the identification of prognostic and predictive markers for patients with genitourinary tumours.

Conflicts of Interest: The authors declare no conflict of interest for this manuscript.

\section{References}

1. Sung, H.; Ferlay, J.; Siegel, R.L.; Laversanne, M.; Soerjomataram, I.; Jemal, A.; Bray, F. Global Cancer Statistics 2020: GLOBOCAN Estimates of Incidence and Mortality Worldwide for 36 Cancers in 185 Countries. CA Cancer J. Clin. 2021, 71, 209-249. [CrossRef]

2. Mori, K.; Pradere, B.; Moschini, M.; Mostafaei, H.; Laukhtina, E.; Schuettfort, V.M.; Sari Motlagh, R.; Soria, F.; Teoh, J.Y.C.; Egawa, S.; et al. First-Line Immune-Checkpoint Inhibitor Combination Therapy for Chemotherapy-Eligible Patients with Metastatic Urothelial Carcinoma: A Systematic Review and Meta-Analysis. Eur. J. Cancer 2021, 151, 35-48. [CrossRef] [PubMed]

3. Lopez-Beltran, A.; Cimadamore, A.; Blanca, A.; Massari, F.; Vau, N.; Scarpelli, M.; Cheng, L.; Montironi, R. Immune Checkpoint Inhibitors for the Treatment of Bladder Cancer. Cancers 2021, 13, 131. [CrossRef] [PubMed]

4. Lattanzi, M.; Rosenberg, J.E. The Emerging Role of Antibody-Drug Conjugates in Urothelial Carcinoma. Expert Rev. Anticancer Ther. 2020, 20, 551-561. [CrossRef]

5. Loriot, Y.; Necchi, A.; Park, S.H.; Garcia-Donas, J.; Huddart, R.; Burgess, E.; Fleming, M.; Rezazadeh, A.; Mellado, B.; Varlamov, S.; et al. Erdafitinib in Locally Advanced or Metastatic Urothelial Carcinoma. N. Engl. J. Med. 2019, 381, 338-348. [CrossRef] [PubMed]

6. Patel, A.; Bisno, D.I.; Patel, H.V.; Ghodoussipour, S.; Saraiya, B.; Mayer, T.; Singer, E.A. Immune Checkpoint Inhibitors in the Management of Urothelial Carcinoma. J. Cancer Immunol. 2021, 3, 115-136. [CrossRef]

7. Dykewicz, C.A.; Centers for Disease Control and Prevention (US). Infectious Diseases Society of America, American Society of Blood and Marrow Transplantation Summary of the Guidelines for Preventing Opportunistic Infections among Hematopoietic Stem Cell Transplant Recipients. Clin. Infect. Dis. 2001, 33, 139-144. [CrossRef] [PubMed]

8. Alexandrov, L.B.; Nik-Zainal, S.; Wedge, D.C.; Aparicio, S.A.J.R.; Behjati, S.; Biankin, A.V.; Bignell, G.R.; Bolli, N.; Borg, A.; Børresen-Dale, A.-L.; et al. Signatures of Mutational Processes in Human Cancer. Nature 2013, 500, 415-421. [CrossRef]

9. Kamoun, A.; de Reyniès, A.; Allory, Y.; Sjödahl, G.; Robertson, A.G.; Seiler, R.; Hoadley, K.A.; Groeneveld, C.S.; Al-Ahmadie, H.; Choi, W.; et al. A Consensus Molecular Classification of Muscle-Invasive Bladder Cancer. Eur. Urol. 2020, 77, 420-433. [CrossRef] [PubMed]

10. Choi, W.; Porten, S.; Kim, S.; Willis, D.; Plimack, E.R.; Hoffman-Censits, J.; Roth, B.; Cheng, T.; Tran, M.; Lee, I.-L.; et al. Identification of Distinct Basal and Luminal Subtypes of Muscle-Invasive Bladder Cancer with Different Sensitivities to Frontline Chemotherapy. Cancer Cell 2014, 25, 152-165. [CrossRef] [PubMed]

11. Rosenberg, J.E.; Hoffman-Censits, J.; Powles, T.; van der Heijden, M.S.; Balar, A.V.; Necchi, A.; Dawson, N.; O’Donnell, P.H.; Balmanoukian, A.; Loriot, Y.; et al. Atezolizumab in Patients with Locally Advanced and Metastatic Urothelial Carcinoma Who Have Progressed Following Treatment with Platinum-Based Chemotherapy: A Single-Arm, Multicentre, Phase 2 Trial. Lancet 2016, 387, 1909-1920. [CrossRef]

12. Seiler, R.; Ashab, H.A.D.; Erho, N.; van Rhijn, B.W.G.; Winters, B.; Douglas, J.; Van Kessel, K.E.; Fransen van de Putte, E.E.; Sommerlad, M.; Wang, N.Q.; et al. Impact of Molecular Subtypes in Muscle-Invasive Bladder Cancer on Predicting Response and Survival after Neoadjuvant Chemotherapy. Eur. Urol. 2017, 72, 544-554. [CrossRef] [PubMed]

13. Mariathasan, S.; Turley, S.J.; Nickles, D.; Castiglioni, A.; Yuen, K.; Wang, Y.; Kadel, E.E.; Koeppen, H.; Astarita, J.L.; Cubas, R.; et al. TGF $\beta$ Attenuates Tumour Response to PD-L1 Blockade by Contributing to Exclusion of T Cells. Nature 2018, 554, 544-548. [CrossRef]

14. Galsky, M.D.; Retz, M.; Siefker-Radtke, A.O.; Baron, A.; Necchi, A.; Bedke, J.; Plimack, E.R.; Vaena, D.; Grimm, M.-O.; Bracarda, S.; et al. Efficacy and Safety of Nivolumab Monotherapy in Patients with Metastatic Urothelial Cancer (MUC) Who Have Received Prior Treatment: Results from the Phase II CheckMate 275 Study. Ann. Oncol. 2016, 27, vi567. [CrossRef]

15. Lindskrog, S.V.; Prip, F.; Lamy, P.; Taber, A.; Groeneveld, C.S.; Birkenkamp-Demtröder, K.; Jensen, J.B.; Strandgaard, T.; Nordentoft, I.; Christensen, E.; et al. An Integrated Multi-Omics Analysis Identifies Prognostic Molecular Subtypes of NonMuscle-Invasive Bladder Cancer. Nat. Commun. 2021, 12, 2301. [CrossRef]

16. van Kessel, K.E.M.; van der Keur, K.A.; Dyrskjøt, L.; Algaba, F.; Welvaart, N.Y.C.; Beukers, W.; Segersten, U.; Keck, B.; Maurer, T.; Simic, T.; et al. Molecular Markers Increase Precision of the European Association of Urology Non-Muscle-Invasive Bladder Cancer Progression Risk Groups. Clin. Cancer Res. 2018, 24, 1586-1593. [CrossRef]

17. Hurst, C.D.; Platt, F.M.; Taylor, C.F.; Knowles, M.A. Novel Tumor Subgroups of Urothelial Carcinoma of the Bladder Defined by Integrated Genomic Analysis. Clin. Cancer Res. 2012, 18, 5865-5877. [CrossRef] 
18. Meléndez, B.; Van Campenhout, C.; Rorive, S.; Remmelink, M.; Salmon, I.; D’Haene, N. Methods of Measurement for Tumor Mutational Burden in Tumor Tissue. Transl. Lung Cancer Res. 2018, 7, 661-667. [CrossRef] [PubMed]

19. Chan, T.A.; Yarchoan, M.; Jaffee, E.; Swanton, C.; Quezada, S.A.; Stenzinger, A.; Peters, S. Development of Tumor Mutation Burden as an Immunotherapy Biomarker: Utility for the Oncology Clinic. Ann. Oncol. 2019, 30, 44-56. [CrossRef]

20. Klempner, S.J.; Fabrizio, D.; Bane, S.; Reinhart, M.; Peoples, T.; Ali, S.M.; Sokol, E.S.; Frampton, G.; Schrock, A.B.; Anhorn, R.; et al. Tumor Mutational Burden as a Predictive Biomarker for Response to Immune Checkpoint Inhibitors: A Review of Current Evidence. Oncologist 2020, 25, e147-e159. [CrossRef]

21. Subbiah, V.; Solit, D.B.; Chan, T.A.; Kurzrock, R. The FDA Approval of Pembrolizumab for Adult and Pediatric Patients with Tumor Mutational Burden (TMB) $\geq 10$ : A Decision Centered on Empowering Patients and Their Physicians. Ann. Oncol. 2020, 31, 1115-1118. [CrossRef] [PubMed]

22. Marabelle, A.; Fakih, M.; Lopez, J.; Shah, M.; Shapira-Frommer, R.; Nakagawa, K.; Chung, H.C.; Kindler, H.L.; Lopez-Martin, J.A.; Miller, W.H.; et al. Association of Tumour Mutational Burden with Outcomes in Patients with Advanced Solid Tumours Treated with Pembrolizumab: Prospective Biomarker Analysis of the Multicohort, Open-Label, Phase 2 KEYNOTE-158 Study. Lancet Oncol. 2020, 21, 1353-1365. [CrossRef]

23. Balar, A.V.; Galsky, M.D.; Rosenberg, J.E.; Powles, T.; Petrylak, D.P.; Bellmunt, J.; Loriot, Y.; Necchi, A.; Hoffman-Censits, J.; Perez-Gracia, J.L.; et al. Atezolizumab as First-Line Treatment in Cisplatin-Ineligible Patients with Locally Advanced and Metastatic Urothelial Carcinoma: A Single-Arm, Multicentre, Phase 2 Trial. Lancet 2017, 389, 67-76. [CrossRef]

24. Powles, T.; Park, S.H.; Voog, E.; Caserta, C.; Valderrama, B.P.; Gurney, H.; Kalofonos, H.; Radulović, S.; Demey, W.; Ullén, A.; et al. Avelumab Maintenance Therapy for Advanced or Metastatic Urothelial Carcinoma. N. Engl. J. Med. 2020, 383, 1218-1230. [CrossRef]

25. Karn, T.; Denkert, C.; Weber, K.E.; Holtrich, U.; Hanusch, C.; Sinn, B.V.; Higgs, B.W.; Jank, P.; Sinn, H.P.; Huober, J.; et al. Tumor Mutational Burden and Immune Infiltration as Independent Predictors of Response to Neoadjuvant Immune Checkpoint Inhibition in Early TNBC in GeparNuevo. Ann. Oncol. 2020, 31, 1216-1222. [CrossRef]

26. Rozeman, E.A.; Hoefsmit, E.P.; Reijers, I.L.M.; Saw, R.P.M.; Versluis, J.M.; Krijgsman, O.; Dimitriadis, P.; Sikorska, K.; van de Wiel, B.A.; Eriksson, H.; et al. Survival and Biomarker Analyses from the OpACIN-Neo and OpACIN Neoadjuvant Immunotherapy Trials in Stage III Melanoma. Nat. Med. 2021, 27, 256-263. [CrossRef]

27. Necchi, A.; Raggi, D.; Gallina, A.; Madison, R.; Colecchia, M.; Lucianò, R.; Montironi, R.; Giannatempo, P.; Farè, E.; Pederzoli, F.; et al. Updated Results of PURE-01 with Preliminary Activity of Neoadjuvant Pembrolizumab in Patients with Muscle-Invasive Bladder Carcinoma with Variant Histologies. Eur. Urol. 2020, 77, 439-446. [CrossRef]

28. Galsky, M.D.; Banchereau, R.; Hamidi, H.R.; Leng, N.; Harris, W.; O’Donnell, P.H.; Kadel, E.E.; Yuen, K.C.Y.; Jin, D.; Koeppen, H.; et al. Tumor, Immune, and Stromal Characteristics Associated with Clinical Outcomes with Atezolizumab (Atezo) + Platinum-Based Chemotherapy (PBC) or Atezo Monotherapy (Mono) versus PBC in Metastatic Urothelial Cancer (MUC) from the Phase III IMvigor130 Study. JCO 2020, 38, 5011. [CrossRef]

29. Addeo, A.; Banna, G.L.; Weiss, G.J. Tumor Mutation Burden-From Hopes to Doubts. JAMA Oncol. 2019, 5, 934-935. [CrossRef] [PubMed]

30. Allen, E.M.V.; Mouw, K.W.; Kim, P.; Iyer, G.; Wagle, N.; Al-Ahmadie, H.; Zhu, C.; Ostrovnaya, I.; Kryukov, G.V.; O'Connor, K.W.; et al. Somatic ERCC2 Mutations Correlate with Cisplatin Sensitivity in Muscle-Invasive Urothelial Carcinoma. Cancer Discov. 2014, 4 1140-1153. [CrossRef] [PubMed]

31. Plimack, E.R.; Dunbrack, R.L.; Brennan, T.A.; Andrake, M.D.; Zhou, Y.; Serebriiskii, I.G.; Slifker, M.; Alpaugh, K.; Dulaimi, E.; Palma, N.; et al. Defects in DNA Repair Genes Predict Response to Neoadjuvant Cisplatin-Based Chemotherapy in MuscleInvasive Bladder Cancer. Eur. Urol. 2015, 68, 959-967. [CrossRef]

32. Nilsson, R.; Björkegren, J.; Tegnér, J. On Reliable Discovery of Molecular Signatures. BMC Bioinform. 2009, 10, 38. [CrossRef] [PubMed]

33. Sung, J.; Wang, Y.; Chandrasekaran, S.; Witten, D.M.; Price, N.D. Molecular Signatures from Omics Data: From Chaos to Consensus. Biotechnol. J. 2012, 7, 946-957. [CrossRef]

34. Sharma, P.; Siddiqui, B.A.; Anandhan, S.; Yadav, S.S.; Subudhi, S.K.; Gao, J.; Goswami, S.; Allison, J.P. The Next Decade of Immune Checkpoint Therapy. Cancer Discov. 2021, 11, 838-857. [CrossRef]

35. Lopez-Beltran, A.; López-Rios, F.; Montironi, R.; Wildsmith, S.; Eckstein, M. Immune Checkpoint Inhibitors in Urothelial Carcinoma: Recommendations for Practical Approaches to PD-L1 and Other Potential Predictive Biomarker Testing. Cancers 2021, 13, 1424. [CrossRef]

36. Mullane, S.A.; Werner, L.; Rosenberg, J.; Signoretti, S.; Callea, M.; Choueiri, T.K.; Freeman, G.J.; Bellmunt, J. Correlation of Apobec Mrna Expression with Overall Survival and Pd-L1 Expression in Urothelial Carcinoma. Sci. Rep. 2016, 6, 27702. [CrossRef]

37. Glaser, A.P.; Fantini, D.; Wang, Y.; Yu, Y.; Rimar, K.J.; Podojil, J.R.; Miller, S.D.; Meeks, J.J. APOBEC-Mediated Mutagenesis in Urothelial Carcinoma Is Associated with Improved Survival, Mutations in DNA Damage Response Genes, and Immune Response. Oncotarget 2018, 9, 4537-4548. [CrossRef]

38. Tu, M.M.; Ng, T.L.; De Jong, F.C.; Zuiverloon, T.C.M.; Fazzari, F.G.T.; Theodorescu, D. Molecular Biomarkers of Response to PD-1/ PD-L1 Immune Checkpoint Blockade in Advanced Bladder Cancer. Bladder Cancer 2019, 5, 131-145. [CrossRef] [PubMed] 
39. Powles, T.; Kockx, M.; Rodriguez-Vida, A.; Duran, I.; Crabb, S.J.; Van Der Heijden, M.S.; Szabados, B.; Pous, A.F.; Gravis, G.; Herranz, U.A.; et al. Clinical Efficacy and Biomarker Analysis of Neoadjuvant Atezolizumab in Operable Urothelial Carcinoma in the ABACUS Trial. Nat. Med. 2019, 25, 1706-1714. [CrossRef] [PubMed]

40. Necchi, A.; Anichini, A.; Raggi, D.; Briganti, A.; Massa, S.; Lucianò, R.; Colecchia, M.; Giannatempo, P.; Mortarini, R.; Bianchi, M.; et al. Pembrolizumab as Neoadjuvant Therapy before Radical Cystectomy in Patients With Muscle-Invasive Urothelial Bladder Carcinoma (PURE-01): An Open-Label, Single-Arm, Phase II Study. J. Clin. Oncol. 2018, 36, 3353-3360. [CrossRef]

41. Powles, T.; Carroll, D.; Chowdhury, S.; Gravis, G.; Joly, F.; Carles, J.; Fléchon, A.; Maroto, P.; Petrylak, D.; Rolland, F.; et al. An Adaptive, Biomarker-Directed Platform Study of Durvalumab in Combination with Targeted Therapies in Advanced Urothelial Cancer. Nat. Med. 2021, 27, 793-801. [CrossRef]

42. Cabel, L.; Proudhon, C.; Romano, E.; Girard, N.; Lantz, O.; Stern, M.-H.; Pierga, J.-Y.; Bidard, F.-C. Clinical Potential of Circulating Tumour DNA in Patients Receiving Anticancer Immunotherapy. Nat. Rev. Clin. Oncol. 2018, 15, 639-650. [CrossRef]

43. Corcoran, R.B.; Chabner, B.A. Application of Cell-Free DNA Analysis to Cancer Treatment. N. Engl. J. Med. 2018, 379, 1754-1765. [CrossRef] [PubMed]

44. Birkenkamp-Demtröder, K.; Christensen, E.; Nordentoft, I.; Knudsen, M.; Taber, A.; Høyer, S.; Lamy, P.; Agerbæk, M.; Jensen, J.B.; Dyrskjøt, L. Monitoring Treatment Response and Metastatic Relapse in Advanced Bladder Cancer by Liquid Biopsy Analysis. Eur. Urol. 2018, 73, 535-540. [CrossRef]

45. Patel, K.M.; van der Vos, K.E.; Smith, C.G.; Mouliere, F.; Tsui, D.; Morris, J.; Chandrananda, D.; Marass, F.; van den Broek, D.; Neal, D.E.; et al. Association of Plasma and Urinary Mutant DNA with Clinical Outcomes in Muscle Invasive Bladder Cancer. Sci. Rep. 2017, 7, 5554. [CrossRef]

46. Vandekerkhove, G.; Lavoie, J.-M.; Annala, M.; Murtha, A.J.; Sundahl, N.; Walz, S.; Sano, T.; Taavitsainen, S.; Ritch, E.; Fazli, L.; et al. Plasma CtDNA Is a Tumor Tissue Surrogate and Enables Clinical-Genomic Stratification of Metastatic Bladder Cancer. Nat. Commun. 2021, 12, 184. [CrossRef]

47. Christensen, E.; Birkenkamp-Demtröder, K.; Sethi, H.; Shchegrova, S.; Salari, R.; Nordentoft, I.; Wu, H.-T.; Knudsen, M.; Lamy, P.; Lindskrog, S.V.; et al. Early Detection of Metastatic Relapse and Monitoring of Therapeutic Efficacy by Ultra-Deep Sequencing of Plasma Cell-Free DNA in Patients with Urothelial Bladder Carcinoma. J. Clin. Oncol. 2019, 37, 1547-1557. [CrossRef]

48. Powles, T.B.; Assaf, Z.J.; Davarpanah, N.; Hussain, M.; Oudard, S.; Gschwend, J.E.; Albers, P.; Castellano, D.; Nishiyama, H.; Daneshmand, S.; et al. $1 O$ Clinical Outcomes in Post-Operative CtDNA-Positive Muscle-Invasive Urothelial Carcinoma (MIUC) Patients after Atezolizumab Adjuvant Therapy. Ann. Oncol. 2020, 31, S1417. [CrossRef]

49. O’Donnell, P.H.; Balar, A.V.; Vuky, J.; Castellano, D.; Bellmunt, J.; Powles, T.; Bajorin, D.F.; Grivas, P.; Hahn, N.M.; Plimack, E.R.; et al. First-Line Pembrolizumab (Pembro) in Cisplatin-Ineligible Patients with Advanced Urothelial Cancer (UC): Response and Survival Results up to Five Years from the KEYNOTE-052 Phase 2 Study. JCO 2021, 39, 4508. [CrossRef]

50. Alva, A.; Csőszi, T.; Ozguroglu, M.; Matsubara, N.; Geczi, L.; Cheng, S.Y.-S.; Fradet, Y.; Oudard, S.; Vulsteke, C.; Barrera, R.M.; et al. LBA23 Pembrolizumab (P) Combined with Chemotherapy (C) vs C Alone as First-Line (1L) Therapy for Advanced Urothelial Carcinoma (UC): KEYNOTE-361. Ann. Oncol. 2020, 31, S1155. [CrossRef]

51. Galsky, M.D.; Arija, J.Á.A.; Bamias, A.; Davis, I.D.; De Santis, M.; Kikuchi, E.; Garcia-Del-Muro, X.; De Giorgi, U.; Mencinger, M.; Izumi, K.; et al. Atezolizumab with or without Chemotherapy in Metastatic Urothelial Cancer (IMvigor130): A Multicentre, Randomised, Placebo-Controlled Phase 3 Trial. Lancet 2020, 395, 1547-1557. [CrossRef]

52. Powles, T.; van der Heijden, M.S.; Castellano, D.; Galsky, M.D.; Loriot, Y.; Petrylak, D.P.; Ogawa, O.; Park, S.H.; Lee, J.-L.; De Giorgi, U.; et al. Durvalumab Alone and Durvalumab plus Tremelimumab versus Chemotherapy in Previously Untreated Patients with Unresectable, Locally Advanced or Metastatic Urothelial Carcinoma (DANUBE): A Randomised, Open-Label, Multicentre, Phase 3 Trial. Lancet Oncol. 2020, 21, 1574-1588. [CrossRef]

53. Powles, T.B.; Loriot, Y.; Bellmunt, J.; Sternberg, C.N.; Sridhar, S.; Petrylak, D.P.; Tambaro, R.; Dourthe, L.M.; Alvarez-Fernandez, C.; Aarts, M.; et al. 699 O Avelumab First-Line (1L) Maintenance + Best Supportive Care (BSC) vs. BSC Alone for Advanced Urothelial Carcinoma (UC): Association between Clinical Outcomes and Exploratory Biomarkers. Ann. Oncol. 2020, 31, S552-S553. [CrossRef]

54. Hussain, M.H.A.; Powles, T.; Albers, P.; Castellano, D.; Daneshmand, S.; Gschwend, J.; Nishiyama, H.; Oudard, S.; Tayama, D.; Davarpanah, N.N.; et al. IMvigor010: Primary Analysis from a Phase III Randomized Study of Adjuvant Atezolizumab (Atezo) versus Observation (Obs) in High-Risk Muscle-Invasive Urothelial Carcinoma (MIUC). JCO 2020, 38, 5000. [CrossRef]

55. Bajorin, D.F.; Witjes, J.A.; Gschwend, J.E.; Schenker, M.; Valderrama, B.P.; Tomita, Y.; Bamias, A.; Lebret, T.; Shariat, S.F.; Park, S.H.; et al. Adjuvant Nivolumab versus Placebo in Muscle-Invasive Urothelial Carcinoma. N. Engl. J. Med. 2021, 384, 2102-2114. [CrossRef] [PubMed]

56. Powles, T.; Durán, I.; van der Heijden, M.S.; Loriot, Y.; Vogelzang, N.J.; De Giorgi, U.; Oudard, S.; Retz, M.M.; Castellano, D.; Bamias, A.; et al. Atezolizumab versus Chemotherapy in Patients with Platinum-Treated Locally Advanced or Metastatic Urothelial Carcinoma (IMvigor211): A Multicentre, Open-Label, Phase 3 Randomised Controlled Trial. Lancet 2018, 391, 748-757. [CrossRef]

57. Bellmunt, J.; de Wit, R.; Vaughn, D.J.; Fradet, Y.; Lee, J.-L.; Fong, L.; Vogelzang, N.J.; Climent, M.A.; Petrylak, D.P.; Choueiri, T.K.; et al. Pembrolizumab as Second-Line Therapy for Advanced Urothelial Carcinoma. N. Engl. J. Med. 2017, 376, 1015-1026. [CrossRef] 
58. Banna, G.L.; Cantale, O.; Bersanelli, M.; Del Re, M.; Friedlaender, A.; Cortellini, A.; Addeo, A. Are Anti-PD1 and Anti-PD-L1 Alike? The Non-Small-Cell Lung Cancer Paradigm. Oncol. Rev. 2020, 14, 490. [CrossRef]

59. Bajorin, D.F.; Dodd, P.M.; Mazumdar, M.; Fazzari, M.; McCaffrey, J.A.; Scher, H.I.; Herr, H.; Higgins, G.; Boyle, M.G. Long-Term Survival in Metastatic Transitional-Cell Carcinoma and Prognostic Factors Predicting Outcome of Therapy. J. Clin. Oncol. 1999, 17, 3173-3181. [CrossRef]

60. Bellmunt, J.; Choueiri, T.K.; Fougeray, R.; Schutz, F.A.B.; Salhi, Y.; Winquist, E.; Culine, S.; von der Maase, H.; Vaughn, D.J.; Rosenberg, J.E. Prognostic Factors in Patients with Advanced Transitional Cell Carcinoma of the Urothelial Tract Experiencing Treatment Failure with Platinum-Containing Regimens. J. Clin. Oncol. 2010, 28, 1850-1855. [CrossRef]

61. Sonpavde, G.; Pond, G.R.; Fougeray, R.; Choueiri, T.K.; Qu, A.Q.; Vaughn, D.J.; Niegisch, G.; Albers, P.; James, N.D.; Wong, Y.-N.; et al. Time from Prior Chemotherapy Enhances Prognostic Risk Grouping in the Second-Line Setting of Advanced Urothelial Carcinoma: A Retrospective Analysis of Pooled, Prospective Phase 2 Trials. Eur. Urol. 2013, 63, 717-723. [CrossRef]

62. Matsumoto, R.; Abe, T.; Ishizaki, J.; Kikuchi, H.; Harabayashi, T.; Minami, K.; Sazawa, A.; Mochizuki, T.; Akino, T.; Murakumo, M.; et al. Outcome and Prognostic Factors in Metastatic Urothelial Carcinoma Patients Receiving Second-Line Chemotherapy: An Analysis of Real-World Clinical Practice Data in Japan. Jpn. J. Clin. Oncol. 2018, 48, 771-776. [CrossRef]

63. Shabto, J.M.; Martini, D.J.; Liu, Y.; Ravindranathan, D.; Brown, J.; Hitron, E.E.; Russler, G.A.; Caulfield, S.; Kissick, H.; Alemozaffar, M.; et al. Novel Risk Group Stratification for Metastatic Urothelial Cancer Patients Treated with Immune Checkpoint Inhibitors. Cancer Med. 2020, 9, 2752-2760. [CrossRef]

64. Suh, J.; Jung, J.H.; Jeong, C.W.; Kwak, C.; Kim, H.H.; Ku, J.H. Clinical Significance of Pre-Treated Neutrophil-Lymphocyte Ratio in the Management of Urothelial Carcinoma: A Systemic Review and Meta-Analysis. Front. Oncol. 2019, 9, 1365. [CrossRef] [PubMed]

65. Kobayashi, K.; Suzuki, K.; Hiraide, M.; Aoyama, T.; Yokokawa, T.; Shikibu, S.; Hashimoto, K.; Iikura, Y.; Sato, H.; Sugiyama, E.; et al. Association of Immune-Related Adverse Events with Pembrolizumab Efficacy in the Treatment of Advanced Urothelial Carcinoma. Oncology 2020, 98, 237-242. [CrossRef]

66. Khaki, A.R.; Li, A.; Diamantopoulos, L.N.; Bilen, M.A.; Santos, V.; Esther, J.; Morales-Barrera, R.; Devitt, M.; Nelson, A.; Hoimes, C.J.; et al. Impact of Performance Status on Treatment Outcomes: A Real-World Study of Advanced Urothelial Cancer Treated with Immune Checkpoint Inhibitors. Cancer 2020, 126, 1208-1216. [CrossRef]

67. Furubayashi, N.; Negishi, T.; Miura, A.; Nakamura, N.; Nakamura, M. Organ-Specific Therapeutic Effect of Paclitaxel and Carboplatin Chemotherapy After Platinum-Based Chemotherapy and Pembrolizumab for Metastatic Urothelial Carcinoma. Res. Rep. Urol. 2020, 12, 455-461. [CrossRef]

68. Ruiz-Bañobre, J.; Molina-Díaz, A.; Fernández-Calvo, O.; Fernández-Núñez, N.; Medina-Colmenero, A.; Santomé, L.; Lázaro-Quintela, M.; Mateos-González, M.; García-Cid, N.; López-López, R.; et al. Rethinking Prognostic Factors in Locally Advanced or Metastatic Urothelial Carcinoma in the Immune Checkpoint Blockade Era: A Multicenter Retrospective Study. ESMO Open 2021, 6, 100090. [CrossRef] [PubMed]

69. Fujiwara, M.; Yuasa, T.; Urasaki, T.; Komai, Y.; Fujiwara, R.; Numao, N.; Yamamoto, S.; Yonese, J. Effectiveness and Safety Profile of Pembrolizumab for Metastatic Urothelial Cancer: A Retrospective Single-Center Analysis in Japan. Cancer Rep. 2021 , e1398. [CrossRef]

70. Tamura, D.; Jinnouchi, N.; Abe, M.; Ikarashi, D.; Matsuura, T.; Kato, R.; Maekawa, S.; Kato, Y.; Kanehira, M.; Takata, R.; et al. Prognostic Outcomes and Safety in Patients Treated with Pembrolizumab for Advanced Urothelial Carcinoma: Experience in Real-World Clinical Practice. Int. J. Clin. Oncol. 2020, 25, 899-905. [CrossRef] [PubMed]

71. Necchi, A.; Fradet, Y.; Bellmunt, J.; de Wit, R.; Lee, J.; Fong, L.; Vozelgang, N.J.; Climent, M.A.; Petrylak, D.P.; Choueiri, T.K.; et al. 3598-Three-Year Follow-Up From the Phase 3 KEYNOTE-045 Trial: Pembrolizumab (Pembro) Versus Investigator's Choice (Paclitaxel, Docetaxel, or Vinflunine) in Recurrent, Advanced Urothelial Cancer (UC). Ann. Oncol. 2019, 30 (Suppl. 5), V356-V402. [CrossRef]

72. Grivas, P.; Park, S.H.; Voog, E.; Caserta, C.; Valderrama, B.P.; Gurney, H.; Kalofonos, H.; Radulovic, S.; Demey, W.; Ullén, A.; et al. 704MO Avelumab First-Line (1L) Maintenance + Best Supportive Care (BSC) vs BSC Alone with 1L Chemotherapy (CTx) for Advanced Urothelial Carcinoma (UC): Subgroup Analyses from JAVELIN Bladder 100. Ann. Oncol. 2020, 31, S555-S556. [CrossRef]

73. Buti, S.; Bersanelli, M.; Perrone, F.; Bracarda, S.; Di Maio, M.; Giusti, R.; Nigro, O.; Cortinovis, D.L.; Aerts, J.G.J.V.; Guaitoli, G.; et al. Predictive Ability of a Drug-Based Score in Patients with Advanced Non-Small-Cell Lung Cancer Receiving First-Line Immunotherapy. Eur. J. Cancer 2021, 150, 224-231. [CrossRef] [PubMed]

74. Cortellini, A.; Tucci, M.; Adamo, V.; Stucci, L.S.; Russo, A.; Tanda, E.T.; Spagnolo, F.; Rastelli, F.; Bisonni, R.; Santini, D.; et al. Integrated Analysis of Concomitant Medications and Oncological Outcomes from PD-1/PD-L1 Checkpoint Inhibitors in Clinical Practice. J. Immunother. Cancer 2020, 8, e001361. [CrossRef] [PubMed]

75. Petrelli, F.; Iaculli, A.; Signorelli, D.; Ghidini, A.; Dottorini, L.; Perego, G.; Ghidini, M.; Zaniboni, A.; Gori, S.; Inno, A. Survival of Patients Treated with Antibiotics and Immunotherapy for Cancer: A Systematic Review and Meta-Analysis. J. Clin. Med. 2020, 9, 1458. [CrossRef] 
76. Rossi, G.; Pezzuto, A.; Sini, C.; Tuzi, A.; Citarella, F.; McCusker, M.G.; Nigro, O.; Tanda, E.; Russo, A. Concomitant Medications during Immune Checkpoint Blockage in Cancer Patients: Novel Insights in This Emerging Clinical Scenario. Crit. Rev. Oncol. Hematol. 2019, 142, 26-34. [CrossRef]

77. Li, C.; Xia, Z.; Li, A.; Meng, J. The Effect of Proton Pump Inhibitor Uses on Outcomes for Cancer Patients Treated with Immune Checkpoint Inhibitors: A Meta-Analysis. Ann. Transl. Med. 2020, 8, 1655. [CrossRef]

78. Xu, H.; He, A.; Liu, A.; Tong, W.; Cao, D. Evaluation of the Prognostic Role of Platelet-Lymphocyte Ratio in Cancer Patients Treated with Immune Checkpoint Inhibitors: A Systematic Review and Meta-Analysis. Int. Immunopharmacol. 2019, $77,105957$. [CrossRef] [PubMed]

79. Lee, K.A.; Shaw, H.M.; Bataille, V.; Nathan, P.; Spector, T.D. Role of the Gut Microbiome for Cancer Patients Receiving Immunotherapy: Dietary and Treatment Implications. Eur. J. Cancer 2020, 138, 149-155. [CrossRef]

80. Hopkins, A.M.; Kichenadasse, G.; Karapetis, C.S.; Rowland, A.; Sorich, M.J. Concomitant Proton Pump Inhibitor Use and Survival in Urothelial Carcinoma Treated with Atezolizumab. Clin. Cancer Res. 2020, 26, 5487-5493. [CrossRef]

81. Hopkins, A.M.; Kichenadasse, G.; Karapetis, C.S.; Rowland, A.; Sorich, M.J. Concomitant Antibiotic Use and Survival in Urothelial Carcinoma Treated with Atezolizumab. Eur. Urol. 2020, 78, 540-543. [CrossRef]

82. Hanahan, D.; Weinberg, R.A. Hallmarks of Cancer: The next Generation. Cell 2011, 144, 646-674. [CrossRef]

83. Templeton, A.J.; McNamara, M.G.; Šeruga, B.; Vera-Badillo, F.E.; Aneja, P.; Ocaña, A.; Leibowitz-Amit, R.; Sonpavde, G.; Knox, J.J.; Tran, B.; et al. Prognostic Role of Neutrophil-to-Lymphocyte Ratio in Solid Tumors: A Systematic Review and Meta-Analysis. J. Natl. Cancer Inst. 2014, 106, dju124. [CrossRef]

84. Templeton, A.J.; Ace, O.; McNamara, M.G.; Al-Mubarak, M.; Vera-Badillo, F.E.; Hermanns, T.; Seruga, B.; Ocaña, A.; Tannock, I.F.; Amir, E. Prognostic Role of Platelet to Lymphocyte Ratio in Solid Tumors: A Systematic Review and Meta-Analysis. Cancer Epidemiol. Biomark. Prev. 2014, 23, 1204-1212. [CrossRef] [PubMed]

85. Kumarasamy, C.; Sabarimurugan, S.; Madurantakam, R.M.; Lakhotiya, K.; Samiappan, S.; Baxi, S.; Nachimuthu, R.; Gothandam, K.M.; Jayaraj, R. Prognostic Significance of Blood Inflammatory Biomarkers NLR, PLR, and LMR in Cancer-A Protocol for Systematic Review and Meta-Analysis. Medicine 2019, 98, e14834. [CrossRef] [PubMed]

86. Rossi, L.; Santoni, M.; Crabb, S.J.; Scarpi, E.; Burattini, L.; Chau, C.; Bianchi, E.; Savini, A.; Burgio, S.L.; Conti, A.; et al. High Neutrophil-to-Lymphocyte Ratio Persistent during First-line Chemotherapy Predicts Poor Clinical Outcome in Patients with Advanced Urothelial Cancer. Ann. Surg. Oncol. 2015, 22, 1377-1384. [CrossRef] [PubMed]

87. Yuk, H.D.; Ku, J.H. Role of Systemic Inflammatory Response Markers in Urothelial Carcinoma. Front. Oncol. 2020, $10,1473$. [CrossRef]

88. Wu, S.; Zhao, X.; Wang, Y.; Zhong, Z.; Zhang, L.; Cao, J.; Ai, K.; Xu, R. Pretreatment Neutrophil-Lymphocyte Ratio as a Predictor in Bladder Cancer and Metastatic or Unresectable Urothelial Carcinoma Patients: A Pooled Analysis of Comparative Studies. Cell. Physiol. Biochem. 2018, 46, 1352-1364. [CrossRef]

89. Xu, H.; Xu, X.; Wang, H.; Ge, W.; Cao, D. The Association between Antibiotics Use and Outcome of Cancer Patients Treated with Immune Checkpoint Inhibitors: A Systematic Review and Meta-Analysis. Crit. Rev. Oncol. Hematol. 2020, 149, 102909. [CrossRef] [PubMed]

90. Sacdalan, D.B.; Lucero, J.A.; Sacdalan, D.L. Prognostic Utility of Baseline Neutrophil-to-Lymphocyte Ratio in Patients Receiving Immune Checkpoint Inhibitors: A Review and Meta-Analysis. Onco Targets Ther. 2018, 11, 955-965. [CrossRef]

91. Banna, G.L.; Signorelli, D.; Metro, G.; Galetta, D.; De Toma, A.; Cantale, O.; Banini, M.; Friedlaender, A.; Pizzutillo, P.; Garassino, M.C.; et al. Neutrophil-to-Lymphocyte Ratio in Combination with PD-L1 or Lactate Dehydrogenase as Biomarkers for High PD-L1 Non-Small Cell Lung Cancer Treated with First-Line Pembrolizumab. Transl. Lung Cancer Res. 2020, 9, $1533-1542$. [CrossRef] [PubMed]

92. Ogihara, K.; Kikuchi, E.; Shigeta, K.; Okabe, T.; Hattori, S.; Yamashita, R.; Yoshimine, S.; Shirotake, S.; Nakazawa, R.; Matsumoto, K.; et al. The Pretreatment Neutrophil-to-Lymphocyte Ratio Is a Novel Biomarker for Predicting Clinical Responses to Pembrolizumab in Platinum-Resistant Metastatic Urothelial Carcinoma Patients. Urol. Oncol. 2020, 38, 602.e1-602.e10. [CrossRef] [PubMed]

93. Shimizu, T.; Miyake, M.; Hori, S.; Ichikawa, K.; Omori, C.; Iemura, Y.; Owari, T.; Itami, Y.; Nakai, Y.; Anai, S.; et al. Clinical Impact of Sarcopenia and Inflammatory/Nutritional Markers in Patients with Unresectable Metastatic Urothelial Carcinoma Treated with Pembrolizumab. Diagnostics 2020, 10, 310. [CrossRef] [PubMed]

94. Brown, J.T.; Liu, Y.; Shabto, J.M.; Martini, D.J.; Ravindranathan, D.; Hitron, E.E.; Russler, G.A.; Caulfield, S.; Yantorni, L.B.; Joshi, S.S.; et al. Baseline Modified Glasgow Prognostic Score Associated with Survival in Metastatic Urothelial Carcinoma Treated with Immune Checkpoint Inhibitors. Oncologist 2021, 26, 397-405. [CrossRef] [PubMed]

95. Yamamoto, Y.; Yatsuda, J.; Shimokawa, M.; Fuji, N.; Aoki, A.; Sakano, S.; Yamamoto, M.; Suga, A.; Tei, Y.; Yoshihiro, S.; et al. Prognostic Value of Pre-Treatment Risk Stratification and Post-Treatment Neutrophil/Lymphocyte Ratio Change for Pembrolizumab in Patients with Advanced Urothelial Carcinoma. Int. J. Clin. Oncol. 2021, 26, 169-177. [CrossRef]

96. Nassar, A.H.; Mouw, K.W.; Jegede, O.; Shinagare, A.B.; Kim, J.; Liu, C.-J.; Pomerantz, M.; Harshman, L.C.; Van Allen, E.M.; Wei, X.X.; et al. A Model Combining Clinical and Genomic Factors to Predict Response to PD-1/PD-L1 Blockade in Advanced Urothelial Carcinoma. Br. J. Cancer 2020, 122, 555-563. [CrossRef] 
97. Khaki, A.R.; Diamantopoulos, L.N.; Li, A.; Devitt, M.E.; Drakaki, A.; Shreck, E.; Joshi, M.; Velho, P.I.; Alonso, L.; Nelson, A.A.; et al. Outcomes of Patients (Pts) with Metastatic Urothelial Cancer (MUC) and Poor Performance Status (PS) Receiving Anti-PD(L)1 Agents. JCO 2019, 37, 4525. [CrossRef]

98. Banna, G.L.; Di Quattro, R.; Malatino, L.; Fornarini, G.; Addeo, A.; Maruzzo, M.; Urzia, V.; Rundo, F.; Lipari, H.; De Giorgi, U.; et al. Neutrophil-to-Lymphocyte Ratio and Lactate Dehydrogenase as Biomarkers for Urothelial Cancer Treated with Immunotherapy. Clin. Transl. Oncol. 2020, 22, 2130-2135. [CrossRef]

99. Prelaj, A.; Rebuzzi, S.E.; Pizzutilo, P.; Bilancia, M.; Montrone, M.; Pesola, F.; Longo, V.; Del Bene, G.; Lapadula, V.; Cassano, F.; et al. EPSILoN: A Prognostic Score Using Clinical and Blood Biomarkers in Advanced Non-Small-Cell Lung Cancer Treated With Immunotherapy. Clin. Lung Cancer 2020, 21, 365-377.e5. [CrossRef]

100. Mezquita, L.; Auclin, E.; Ferrara, R.; Charrier, M.; Remon, J.; Planchard, D.; Ponce, S.; Ares, L.P.; Leroy, L.; Audigier-Valette, C.; et al. Association of the Lung Immune Prognostic Index with Immune Checkpoint Inhibitor Outcomes in Patients with Advanced Non-Small Cell Lung Cancer. JAMA Oncol. 2018, 4, 351-357. [CrossRef]

101. Chrom, P.; Zolnierek, J.; Bodnar, L.; Stec, R.; Szczylik, C. External Validation of the Systemic Immune-Inflammation Index as a Prognostic Factor in Metastatic Renal Cell Carcinoma and Its Implementation within the International Metastatic Renal Cell Carcinoma Database Consortium Model. Int. J. Clin. Oncol. 2019, 24, 526-532. [CrossRef] [PubMed]

102. Martini, D.J.; Liu, Y.; Shabto, J.M.; Carthon, B.C.; Hitron, E.E.; Russler, G.A.; Caulfield, S.; Kissick, H.T.; Harris, W.B.; Kucuk, O.; et al. Novel Risk Scoring System for Patients with Metastatic Renal Cell Carcinoma Treated with Immune Checkpoint Inhibitors. Oncologist 2020, 25, e484-e491. [CrossRef] [PubMed]

103. Rebuzzi, S.E.; Signori, A.; Banna, G.L.; Maruzzo, M.; De Giorgi, U.; Pedrazzoli, P.; Sbrana, A.; Zucali, P.A.; Masini, C.; Naglieri, E.; et al. Inflammatory Indices and Clinical Factors in Metastatic Renal Cell Carcinoma Patients Treated with Nivolumab: The Development of a Novel Prognostic Score (Meet-URO 15 Study). Ther. Adv. Med. Oncol. 2021, 13, 17588359211019642. [CrossRef] [PubMed]

104. Fornarini, G.; Rebuzzi, S.E.; Banna, G.L.; Calabrò, F.; Scandurra, G.; De Giorgi, U.; Masini, C.; Baldessari, C.; Naglieri, E.; Caserta, C.; et al. Immune-Inflammatory Biomarkers as Prognostic Factors for Immunotherapy in Pretreated Advanced Urinary Tract Cancer Patients: An Analysis of the Italian SAUL Cohort. ESMO Open 2021, 6, 100118. [CrossRef]

105. Sonpavde, G.; Manitz, J.; Gao, C.; Tayama, D.; Kaiser, C.; Hennessy, D.; Makari, D.; Gupta, A.; Abdullah, S.E.; Niegisch, G.; et al. Five-Factor Prognostic Model for Survival of Post-Platinum Patients with Metastatic Urothelial Carcinoma Receiving PD-L1 Inhibitors. J. Urol. 2020, 204, 1173-1179. [CrossRef] [PubMed]

106. Abuhelwa, A.Y.; Kichenadasse, G.; McKinnon, R.A.; Rowland, A.; Hopkins, A.M.; Sorich, M.J. Machine Learning for Prediction of Survival Outcomes with Immune-Checkpoint Inhibitors in Urothelial Cancer. Cancers 2021, 13, 2001. [CrossRef]

107. Trebeschi, S.; Drago, S.G.; Birkbak, N.J.; Kurilova, I.; Călin, A.M.; Delli Pizzi, A.; Lalezari, F.; Lambregts, D.M.J.; Rohaan, M.W.; Parmar, C.; et al. Predicting Response to Cancer Immunotherapy Using Noninvasive Radiomic Biomarkers. Ann. Oncol. 2019, 30, 998-1004. [CrossRef]

108. Banna, G.L.; Olivier, T.; Rundo, F.; Malapelle, U.; Fraggetta, F.; Libra, M.; Addeo, A. The Promise of Digital Biopsy for the Prediction of Tumor Molecular Features and Clinical Outcomes Associated With Immunotherapy. Front. Med. 2019, 6, 172. [CrossRef] [PubMed]

109. Wang, J.H.; Wahid, K.A.; van Dijk, L.V.; Farahani, K.; Thompson, R.F.; Fuller, C.D. Radiomic Biomarkers of Tumor Immune Biology and Immunotherapy Response. Clin. Transl. Radiat. Oncol. 2021, 28, 97-115. [CrossRef] [PubMed]

110. Zhang, C.; de Fonseca, L.; Shi, Z.; Zhu, C.; Dekker, A.; Bermejo, I.; Wee, L. Systematic Review of Radiomic Biomarkers for Predicting Immune Checkpoint Inhibitor Treatment Outcomes. Methods 2021, 188, 61-72. [CrossRef]

111. Trebeschi, S.; Bodalal, Z.; Boellaard, T.N.; Tareco Bucho, T.M.; Drago, S.G.; Kurilova, I.; Calin-Vainak, A.M.; Delli Pizzi, A.; Muller, M.; Hummelink, K.; et al. Prognostic Value of Deep Learning-Mediated Treatment Monitoring in Lung Cancer Patients Receiving Immunotherapy. Front. Oncol. 2021, 11, 609054. [CrossRef] [PubMed]

112. Park, K.J.; Lee, J.-L.; Yoon, S.-K.; Heo, C.; Park, B.W.; Kim, J.K. Radiomics-Based Prediction Model for Outcomes of PD-1/PD-L1 Immunotherapy in Metastatic Urothelial Carcinoma. Eur. Radiol. 2020, 30, 5392-5403. [CrossRef] [PubMed]

113. Rundo, F.; Bersanelli, M.; Urzia, V.; Friedlaender, A.; Cantale, O.; Calcara, G.; Addeo, A.; Banna, G.L. Three-Dimensional Deep Noninvasive Radiomics for the Prediction of Disease Control in Patients With Metastatic Urothelial Carcinoma Treated With Immunotherapy. Clin. Genitourin. Cancer 2021, 19, 396-404. [CrossRef] [PubMed] 